\title{
PENGARUH BAURAN PEMASARAN TERHADAP KEPUTUSAN PEMBELIAN SMARTPHONE MEREK SAMSUNG PADA MAHASISWA UNIVERSITAS ALKHAIRAAT PALU
}

\author{
Heni Susanti \\ Maskuri Sutomo \\ Benyamin Parubak \\ Jurusan Manajemen, Fakultas Ekonomi, Universitas Tadulako \\ Email: heni.susmeka@gmail.com
}

\begin{abstract}
The purpose of this study to determine and analyze the influence of marketing mix on purchasing decisions of Samsung smartphone in Alkhairaat University's students in Palu. Type of research is descriptive causal using purposive sampling technique, with a sample of 60 respondents. Method of analysis is multiple linear regressiosn by using computer program SPSS for Windows Release 16.0. The Hypothesis test show a significance level $\alpha=0.05$ and for the reliability test shows cronbach alpha coefficient values with the limit value coefficient of $\alpha=0.60$. The results of this study show that marketing mix significantly influences purchasing decisions with sig. value of 0,000. Partial test with standard $\alpha=0.05$ shows the results of products $(X 1)$, price $(X 2)$, points $(X 3)$, and promotion $(X 4)$ significantly influence purchasing decisions with sig. value of 0,007, 0,000. 0.012, and 0.000, respectively. Alla variables have influence on purchasing decisions of 0.876 or $87.6 \%$, while the remaining $12.4 \%$ is influenced by other variables.
\end{abstract}

Keywords: marketing mix, purchasing decisions, smartphones Samsung

\section{ABSTRAK}

Tujuan penelitian ini untuk mengetahui dan menganalisis pengaruh bauran pemasaran terhadap keputusan pembelian smartphone merek Samsung pada mahasiswa Universitas Alkhairaat Palu. Jenis penelitian yang digunakan adalah deskriptif kausal, menggunakan teknik penarikan sampel Purposive Sampling, dengan jumlah sampel 60 responden. Metode analisis yang digunakan yaitu Analisis Regresi Linear Berganda dengan menggunakan bantuan dari program komputer SPSS for Windows Release 16,0. Uji hipotesis yang digunakan mempunyai taraf signifikansi $\alpha=0,05$ dan untuk uji reliabilitas menggunakan nilai koefisien croanbach alpha dengan nilai batas koefisien $\alpha=0,60$ Hasil penelitian ini menunjukkan bahwa secara simultan bauran pemasaran berpengaruh signifikan terhadap keputusan pembelian, dengan nilai sig 0,000. Secara parsial dengan standar $\alpha=0,05$ diperoleh hasil penelitian Produk (X1), Harga (X2), Tempat (X3), dan Promosi (X4) berpengaruh signifikan terhadap keputusan pembelian dengan nilai sig masing-masing sebesar 0,007, 0,000. 0,012, dan 0,000. Keempat variabel ini berpengaruh sebesar 0,876 atau 87,6\% terhadap keputusan pembelian sedangkan sisanya sebesar 12,4\% dipengaruhi oleh variabel lain.

Kata Kunci: Bauran Pemasaran, keputusan pembelian dan smartphone Samsung

\section{PENDAHULUAN}

Persaingan dalam dunia pemasaran yang semakin kompetitif menuntut para pemasar untuk terus memberikan nilai lebih kepada konsumen dalam meningkatkan daya saing. Untuk memenuhi kebutuhan dan keinginan konsumen, pemasar perlu melakukan upaya-upaya yang harus terus dikembangkan dari waktu ke waktu demi memperebutkan pasar potensial dan mempertahankan konsumen yang ada. Salah satu bidang usaha yang terus berkembang yaitu bidang teknologi dan komunikasi.

Perkembangan dalam bidang komunikasi saat ini mendorong terciptanya produk-produk alat komunikasi yang semakin maju dan beragam. Alat komunikasi merupakan salah satu kebutuhan bagi konsumen yang harus dipenuhi. Dengan alat komunikasi manusia dapat dengan mudah memperoleh informasi yang dibutuhkan. Dan saat ini telah tercipta smartphone yang perkembangannya sangat pesat 
Susanti, H.

karena hadir dengan berbagai kelebihan yang dapat membantu aktifitas penggunanya. Smartphone menurut Brusco dalam Hasan et al. (2014:688) merupakan mobile phone yang berfungsi seperti sistem komputer, pengiriman pesan (email), mengakses internet dan memiliki berbagai aplikasi sebagai tempat untuk mencari informasi.

Salah satu merek smartphone yang cukup terkenal adalah Samsung. Smartphone merek Samsung saat ini mampu menjadi yang unggul di antara produsen-produsen smartphone lain seperti Apple, Huawei, Oppo dan Vivo. Smartphone Samsung menduduki peringkat teratas dalam market share yang dirilis oleh perusahaan riset International Data Corporation (IDC) Quartal ke-3 pada tahun 2016. Untuk lebih jelasnya dapat dilihat pada Tabel 1 berikut:

Tabel 1 Data Penjualan Smartphone Q32015 dan Q32016

\begin{tabular}{|l|l|l|l|l|l|}
\hline \multicolumn{5}{|c|}{ Top Five Smartphone Vendors, Shipment, Market Share And year-Over -Year Growth, Q3 } \\
2016 Preliminary Data (Units In Millions) \\
\hline Vendor & $\begin{array}{l}\text { 3Q 2016 } \\
\text { Shipment } \\
\text { Volumes }\end{array}$ & $\begin{array}{l}\text { 3Q2016 } \\
\text { Market Share }\end{array}$ & $\begin{array}{l}\text { 3Q 2015 } \\
\text { Shipment } \\
\text { Volumes }\end{array}$ & $\begin{array}{l}\text { 3Q 2015 } \\
\text { Market Share }\end{array}$ & $\begin{array}{l}\text { Year-Over - } \\
\text { Year Growth }\end{array}$ \\
\hline 1.Samsung & 72,5 & $20,0 \%$ & 83,8 & $23,3 \%$ & $-13,5 \%$ \\
\hline 2.Apple & 45,5 & $12,5 \%$ & 48,0 & $13,4 \%$ & $-5,3 \%$ \\
\hline 3.Huawei & 33,6 & $9,3 \%$ & 27,3 & $7,6 \%$ & $23,0 \%$ \\
\hline 4.Oppo & 23,5 & $7,0 \%$ & 11,4 & $3,2 \%$ & $121,6 \%$ \\
\hline 5.Vivo & 21,2 & $4,8 \%$ & 10,3 & $2,9 \%$ & $105,5 \%$ \\
\hline Others & 164,8 & $45,4 \%$ & 178,2 & $49,6 \%$ & $-7,5 \%$ \\
\hline Total & 362,9 & $100,0 \%$ & 359,3 & $100,0 \%$ & $1,0 \%$ \\
\hline Source: IDC Wordwide Quarterly Mobile Phone Tracker, Oktober 26, 2016. \\
\hline
\end{tabular}

Berdasarkan data di atas dapat dilihat bahwa Samsung menguasai pasar smartphone dunia. Samsung tetap mengungguli pesaing beratnya Apple dan pesaing barunya Vivo. Dalam mencapai strategi pemasaran yang tepat dan terbaik untuk diterapkan, salah satunya perusahaan dapat melihat dari faktor bauran pemasaran. Hal tersebut penting karena bauran pemasaran merupakan salah satu pokok pertimbangan konsumen dalam melakukan keputusan pembelian suatu produk. Kotler dan Amstrong (2008:62-63) mengelompokkan bauran pemasaran menjadi empat tahap yang biasa disebut dengan 4p, yaitu terdiri dari Produk (Product), Harga (Price), Tempat (Place), dan Promosi (Promotion).

Berdasarkan pra penelitian yang dilakukan pada mahasiswa Universitas Alkhairaat Palu, ditemukan fakta bahwa ternyata dari setiap mahasiswa Universitas Alkhairaat Palu yang ditemui hampir semuanya menggunakan smartphone merek Samsung. Menurut mahasiswa Universitas Alkhairaat Palu pengguna smartphone merek Samsung terdapat banyak pengaruh yang menonjol sehingga memutuskan untuk membeli dan menggunakan smartphone merek Samsung diantaranya merek yang terkenal dan harga yang bervariasi serta terjangkau.

Berdasarkan uraian di atas, maka peneliti tertarik melakukan penelitian dengan judul: Pengaruh Bauran Pemasaran Terhadap Keputusan Pembelian Smartphone merek Samsung pada Mahasiswa Universitas Alkhairaat Palu. Adapun tujuan yang ingin dicapai dalam penelitian ini adalah sebagai berikut:

1. Untuk menganalisis dan mengetahui pengaruh simultan variabel bauran pemasaran yang terdiri dari produk, harga, tempat, dan promosi terhadap keputusan pembelian smartphone merek

Samsung pada mahasiswa Universitas Alkhairaat Palu 
2. Untuk menganalisis dan mengetahui pengaruh variabel produk terhadap keputusan pembelian smartphone merek Samsung pada mahasiswa Universitas Alkhairaat Palu

3. Untuk menganalisis dan mengetahui pengaruh variabel harga terhadap keputusan pembelian smartphone merek Samsung pada mahasiswa Universitas Alkhairaat Palu

4. Untuk menganalisis dan mengetahui pengaruh variabel tempat terhadap keputusan pembelian smartphone merek Samsung pada mahasiswa Universitas Alkhairaat Palu

5. Untuk menganalisis dan mengetahui pengaruh variabel promosi terhadap keputusan pembelian smartphone merek Samsung pada mahasiswa Universitas Alkhairaat Palu

\section{KAJIAN LITERATUR DAN PENGEMBANGAN HIPOTESIS}

\section{Pengertian Pemasaran}

Kotler dan Keller (2009:5) pemasaran adalah sebuah proses kemasyarakatan dimana individu dan kelompok memperoleh apa yang mereka butuhkan dan inginkan dengan menciptakan, menawarkan, dan secara bebas mempertukarkan produk dan jasa yang bernilai kepada orang lain.

\section{Manajemen Pemasaran}

Manajemen pemasaran (marketing management) adalah proses menganalisis, merencanakan, mengkoordinasikan, dan mengendalikan program-program yang mencakup pengkonsepan, penetapan harga, promosi dan distribusi dari produk, jasa, dan gagasan yang dirancang untuk menciptakan dan memelihara pertukaran yang menguntungkan dengan pasar sasaran untuk mencapai tujuan perusahaan menurut Boyd et al. (2000:18).

\section{Bauran Pemasaran}

Assauri (2009:193) Bauran pemasaran adalah strategi yang dijalankan perusahaan, yang berkaitan dengan penentuan bagaimana perusahaan menyajikan penawaran produk pada segmen pasar tertentu, yang merupakan sasaran pasarnya.

\section{Merek}

American Marketing Association mendefinisikan merek sebagai "nama, istilah, tanda, lambang, atau desain, atau kombinasinya, yang dimaksudkan untuk mengidentifikasi barang atau jasa dari salah satu penjual atau kelompok penjual dan mendiferensiasikan mereka dari para pesaing." (Kotler dan Keller, 2009:258).

\section{Pengertian Perilaku Konsumen}

Menurut Mowen dan Minor (2002:6) perilaku konsumen (consumer behavior) didefinisikan sebagai studi tentang unit pembelian (buying units) dan proses pertukaran yang melibatkan perolehan, konsumsi, dan pembuangan barang, jasa, pengalaman, serta ide-ide.

\section{Proses Pengambilan Keputusan}

Kotler dan Amstrong (2008:179) menjelaskan bahwa proses keputusan terdiri dari lima tahap yaitu pengenalan kebutuhan, pencarian informasi, evaluasi alternatif, keputusan pembelian dan perilaku pasca pembelian. Untuk lebih jelasnya proses keputusan pembelian dapat dilihat pada Gambar 1 berikut ini:

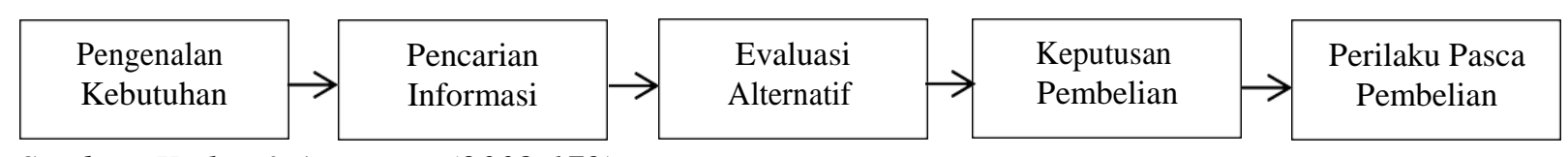

Sumber: Kotler \& Amstrong (2008:179)

\section{Gambar 1 Proses Keputusan Pembelian}




\section{Keputusan Pembelian Konsumen}

Menurut Setiadi (2013:342) pengambilan keputusan konsumen (consumer decision making) adalah proses pengintegrasian yang mengkombinasikan pengetahuan untuk mengevaluasi dua atau lebih perilaku alternatif, dan memilih salah satu diantaranya.

\section{Kerangka Pemikiran}

Kerangka pemikiran dalam penelitian ini dapat dilihat pada gambar di bawah ini:

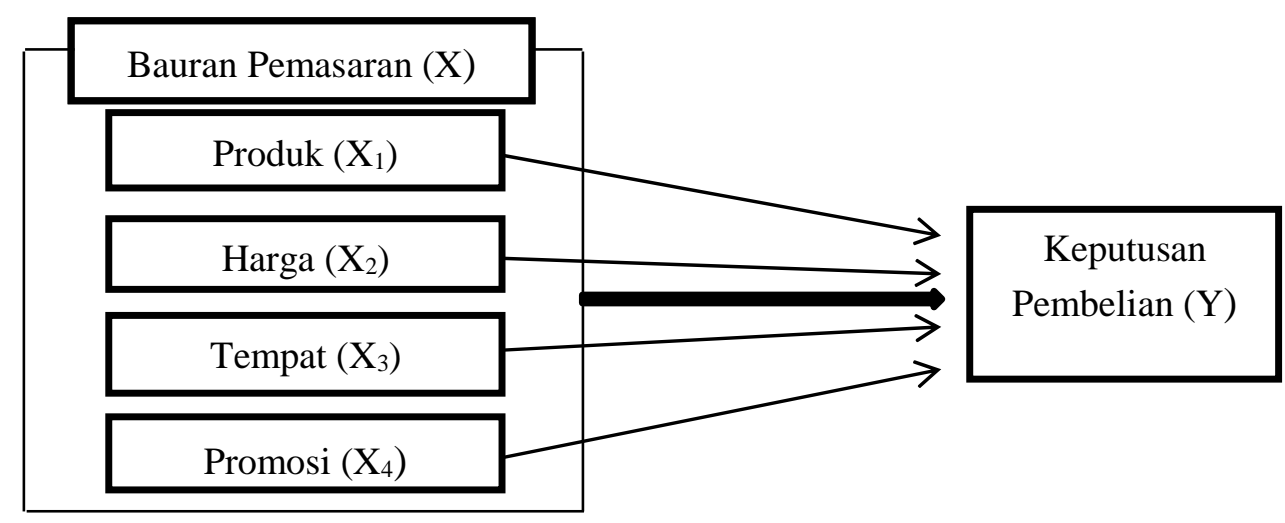

Sumber: Kotler dan Amstrong (2009:62)

\section{Gambar 2 Kerangka Pemikiran}

\section{Hipotesis}

Bauran pemasaran yang terdiri dari produk, harga, tempat, dan promosi secara serempak berpengaruh signifikan terhadap keputusan pembelian smartphone merek Samsung

1. Produk berpengaruh signifikan terhadap keputusan pembelian smartphone merek Samsung

2. Harga berpengaruh signifikan terhadap keputusan pembelian smartphone merek Samsung

3. Tempat berpengaruh signifikan terhadap keputusan pembelian smartphone merek Samsung

4. Promosi berpengaruh signifikan terhadap keputusan pembelian smartphone merek Samsung

\section{METODE PENELITIAN}

Sesuai dengan tujuan penelitian yaitu untuk mengetahui Pengaruh Bauran Pemasaran Terhadap Keputusan Pembelian Smartphone Merek Samsung pada Mahasiswa Universitas Alkharaat Palu. Maka jenis penelitian yang digunakan adalah kuantitatif.

Penelitian dilakukan di Universitas Alkhairaat Palu yang beralamat di Jl. Diponegoro No.39 Palu. Karena peneliti melihat bahwa di Universitas Alkhairaat Palu terdapat banyak mahasiswa yang menggunakan smartphone merek Samsung.

Menurut Sugiyono (2014:115) populasi adalah wilayah generalisasi yang terdiri atas: objek/subyek yang mempunyai kualitas dan karakteristik tertentu yang ditetapkan oleh peneliti untuk dipelajari dan kemudian ditarik kesimpulannya. Dalam penelitian ini yang dimaksud dengan populasi yaitu seluruh mahasiswa pengguna smartphone merek Samsung pada Universitas Alkhairaat Palu. Dalam penelitian ini jumlah variabelnya adalah 5 yang terdiri dari variabel independen (bauran pemasaran) dan variabel dependen (keputusan pembelian). Berdasarkan pertimbangan tersebut maka penulis menetapkan jumlah sampel dengan ketentuan $12 \times 5$ (variabel) $=60$ responden/mahasiswa, dengan demikian jumlah sampel dalam penelitian ini adalah 60 responden..

Pendistribusian tersebut diperoleh dari rumus sebagai berikut:

$$
\frac{\text { jumlah mahasiswa per fakultas }}{\text { jumlah mahasiswa keseluruhan }} \times 100
$$


Berdasarkan hasil persen yang diperoleh dikalikan dengan jumlah responden kemudian dibahagi 100 seperti pada rumus berikut:

$$
\frac{\text { hasil nilai persen } \times \text { jumlah responden }}{100}
$$

Tabel 2 Rumus Hasil Pendistribusian Kuesioner

\begin{tabular}{|c|c|c|c|c|c|}
\hline No. & Fakultas & $\begin{array}{c}\text { Jumlah } \\
\text { Mahasiswa Per } \\
\text { Fakultas }\end{array}$ & $\begin{array}{c}\text { Jumlah Mahasiswa } \\
\text { Keseluruhan }\end{array}$ & Nilai Persen & $\begin{array}{c}\text { Jumlah Sampel Per } \\
\text { Fakultas }\end{array}$ \\
\hline 1. & FKIK & 269 & 2.667 & $10 \%$ & 6 \\
\hline 2. & Faperta & 319 & 2.667 & $12 \%$ & 7 \\
\hline 3. & Perikanan & 49 & 2.667 & $2 \%$ & 1 \\
\hline 4. & Ekonomi & 1.016 & 2.667 & $38 \%$ & 23 \\
\hline 5. & FKIP & 875 & 2.667 & $33 \%$ & 20 \\
\hline 6. & Sastra & 89 & 2.667 & $3 \%$ & 1 \\
\hline 7. & Agama & 29 & 2.667 & $1 \%$ & 1 \\
\hline 8. & Huklam & & 2.667 & $1 \%$ & 1 \\
\hline
\end{tabular}

Sumber: PDPT Universitas Alkhairaat Palu

Metode penarikan sampel yang digunakan adalah Purposive Sampling. Karena jumlah populasi tidak diketahui dan adanya kriteria yang harus dipenuhi untuk menjadi sampel penelitian. Menurut Sugiyono (2014:122) Sampling purposive adalah teknik penentuan sampel dengan pertimbangan tertentu. Adapun kriteria responden yang dijadikan sampel dalam penelitian ini adalah:

1. Responden merupakan mahasiswa Universitas Alkharaat Palu

2. Telah membeli dan menggunakan smartphone merek Samsung

3. Responden merupakan konsumen yang mengambil keputusan untuk membeli smartphone merek Samsung

4. Bersedia mengisi kuesioner yang diberikan peneliti

Metode pengumpulan data dalam penelitian ini, dilakukan dengan langkah-langkah sebagai berikut:

1. Observasi

2. Wawancara

3. Penyebaran Kuisioner

Metode analisis data dalam penelitian ini menggunakan regresi linier berganda. Menurut Sugiyono (2014:277) analisis regresi berganda dilakukan bila jumlah variabel independennya minimal dua. Persamaan regresi untuk $\mathrm{n}$ prediktor adalah sebagai berikut :

$$
\mathrm{Y}=\mathrm{a}+\mathrm{b}_{1} \mathrm{X}_{1}+\mathrm{b}_{2} \mathrm{X}_{2}+\ldots \ldots+\mathrm{b}_{\mathrm{n}} \mathrm{X}_{\mathrm{n}} \text { Dimana: }
$$

$\mathrm{Y}=$ keputusan pembelian $\mathrm{a}=$ Konstanta

$$
\begin{array}{ll}
\mathrm{b}_{1}, \mathrm{~b}_{2} \ldots \ldots \mathrm{b}_{\mathrm{x}} & =\text { Koefisien regresi } \\
\mathrm{X}_{1} \mathrm{X}_{2} \ldots . . \mathrm{X}_{\mathrm{n}} & =\text { Variabel bebas (independen) }
\end{array}
$$

Apabila formulasi matematis regresi linear berganda tersebut diaplikasikan dalam penelitian ini, maka akan diperoleh bentuk persamaan sebagai berikut: $\mathrm{Y}=\mathrm{a}+\mathrm{b}_{1} \mathrm{X}_{1}+\mathrm{b}_{2} \mathrm{X}_{2}+\mathrm{b}_{3} \mathrm{X}_{3}+\mathrm{b}_{4}+\mathrm{X}_{4}$ 
Susanti, H.

Dimana:

$$
\begin{array}{ll}
\mathrm{Y} & =\text { Keputusan pembelian } \\
\mathrm{X}_{1} & =\text { Produk } \\
\mathrm{X}_{2} & =\text { Harga } \\
\mathrm{X}_{3} & =\text { Tempat } \\
\mathrm{X}_{4} & =\text { Promosi } \\
\mathrm{a} & =\text { Konstanta } \\
\mathrm{b}_{1}-\mathrm{b}_{4} & =\text { Koefisien regresi }
\end{array}
$$

\section{Pengujian Hipotesis}

\section{Uji F atau Uji Simultan}

Untuk menguji keberartian dari koefisien regresi secara serempak digunakan dengan kaidah pengambilan keputusan sebagai berikut sesuai hasil yang didapatkan pada perhitungan statistik menggunakan program komputer SPSS 16 :

1. Jika probabilitas (signifikan $F<a=0,05$ ) artinya berpengaruh signifikan pada tingkat kepercayaan $95 \%$, maka terbukti bahwa semua faktor bebas (X) berpengaruh serempak secara nyata (signifikan) terhadap faktor terikat (Y).

2. Jika probabilitas (signifikan $\mathrm{F}>\mathrm{a}=0,05$ ) pada tingkat kepercayaan $95 \%$, maka terbukti bahwa semua faktor bebas (X) tidak berpengaruh serempak secara nyata (signifikan) terhadap faktor terikat (Y).

\section{Uji t atau Uji Parsial}

Untuk menguji pengaruh dari masing-masing faktor bebas secara parsial terhadap faktor terikat (Y) digunakan alat statistik program komputer SPSS 16 dengan kaidah pengambilan keputusan sebagai berikut:

1. Jika probabilitas (signifikan $\mathrm{t}<\operatorname{sig} \mathrm{a}=0,05$ ) artinya pada tingkat kepercayaan $95 \%$, maka terbukti secara parsial faktor bebas (Xi) berpengaruh secara nyata (signifikan) terhadap faktor terikat (Y).

2. Jika probabilitas (signifikan $\mathrm{t}<\mathrm{a}=0,05$ ) artinya pada tingkat kepercayaan $95 \%$, maka terbukti secara parsial faktor bebas (Xi) tidak berpengaruh secara nyata (signifikan) terhadap faktor terikat (Y).

\section{HASIL DAN PEMBAHASAN}

\section{Hasil Analisis Regresi Linear Berganda}

Sesuai analisis Regresi Linear Berganda dengan menggunakan bantuan komputer program SPSS 16 diperoleh hasil perhitungan dari variabel independen produk (X1), harga (X2), tempat (X3), dan promosi (X4) terhadap variabel dependen keputusan pembelian (Y) dapat dilihat pada Tabel berikut:

Tabel 3 Hasil Analisis Regresi Linear Berganda

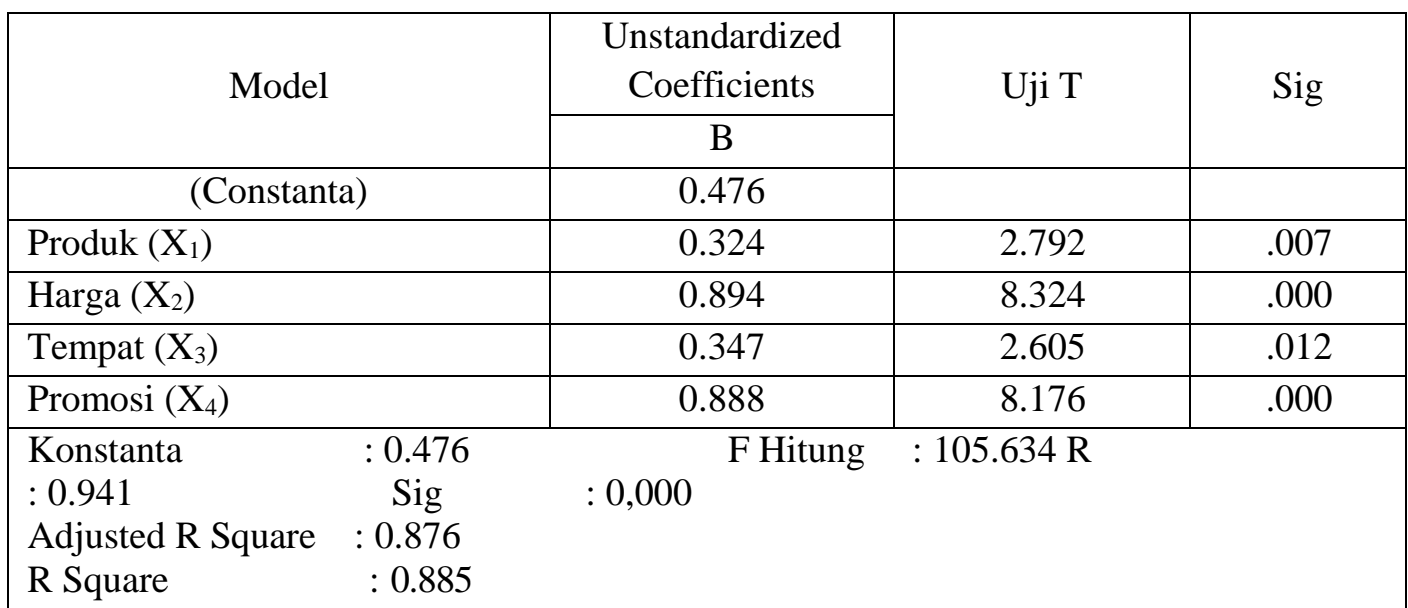

Sumber: Data primer yang diolah kembali melalui SPSS 16 
Berdasarkan uraian Tabel 3 di atas, persamaan regresi yang diperoleh adalah:

$$
\begin{aligned}
& \mathrm{Y}=\mathrm{a}+\mathrm{b} 1 \mathrm{X} 1+\mathrm{b} 2 \mathrm{X} 2+\mathrm{b} 3 \mathrm{X} 3+\mathrm{b} 4 \mathrm{X} 4 \\
& \mathrm{Y}=0,476+0,324 \mathrm{X} 1+0.894 \mathrm{X} 2+0.347 \mathrm{X} 3+0.888 \mathrm{X} 4
\end{aligned}
$$

Persamaan di atas, memperlihatkan nilai konstanta 0,476 yang bermakna bahwa tanpa adanya variabel bebas yaitu produk, harga, tempat, dan promosi, maka keputusan pembelian smartphone merek Samsung pada mahasiswa Universitas Alkhairaat Palu adalah sebesar 0,476.

\section{Pengujian Hipotesis \\ Hasil Uji Simultan (Uji f)}

\begin{tabular}{|c|c|c|c|c|c|c|}
\hline \multicolumn{7}{|c|}{ ANOVA $^{b}$} \\
\hline \multicolumn{2}{|c|}{ Model } & $\begin{array}{l}\text { Sum of } \\
\text { Squares }\end{array}$ & $\mathrm{df}$ & $\begin{array}{l}\text { Mean } \\
\text { Square }\end{array}$ & $\mathrm{F}$ & Sig. \\
\hline \multirow[t]{3}{*}{1} & Regression & 20.458 & 4 & 5.114 & 105.634 & $.000^{\mathrm{a}}$ \\
\hline & Residual & 2.663 & 55 & & & \\
\hline & Total & 23.121 & 59 & & & \\
\hline
\end{tabular}

Tabel 4 Hasil Pengujian Secara Simultan (Uji F)

Sumber: Data primer yang diolah kembali melalui SPSS 16

Berdasarkan hasil pengujian model regresi diperoleh nilai $\mathrm{F}$ sebesar 105.634 dengan signifikansi 0,000 dengan nilai $a=0,05$. Sehingga dapat diketahui bahwa $0,000<0,05$ maka model analisis regresi ini dinyatakan signifikan. Hal ini menyatakan bahwa Ho ditolak dan Ha diterima.

\section{Hasil Uji Parsial (Uji t)}

Hasil uji t atau uji parsial lebih jelasnya dapat dilihat pada penjelasan di bawah ini :

1. Produk $(\mathrm{X} 1)$

Dari hasil pengolahan data yang dilakukan, dapat dilihat besar probabilitas signifikan produk (X1) sebesar $0,007<\alpha 0,05$ maka dapat disimpulkan bahwa variabel produk secara parsial berpengaruh signifikan terhadap keputusan pembelian smartphone merek Samsung pada mahasiswa Universitas Alkhairaat Palu.

2. Harga (X2)

Dari hasil pengolahan data yang dilakukan, dapat dilihat besar probabilitas signifikan harga (X2) sebesar $0,000<\alpha 0,05$ maka dapat disimpulkan bahwa variabel harga secara parsial berpengaruh signifikan terhadap keputusan pembelian smartphone merek Samsung pada mahasiswa Universitas Alkhairaat Palu.

3. Tempat (X3)

Dari hasil pengolahan data yang dilakukan, dapat dilihat besar probabilitas signifikan tempat (X3) sebesar $0,012<\alpha 0,05$ maka dapat disimpulkan bahwa variabel harga secara parsial berpengaruh signifikan terhadap keputusan pembelian smartphone merek Samsung pada mahasiswa Universitas Alkhairaat Palu.

4. Promosi (X4)

Dari hasil pengolahan data yang dilakukan, dapat dilihat besar probabilitas signifikan promosi (X4) sebesar $0,000<\alpha 0,05$ maka dapat disimpulkan bahwa variabel harga secara parsial berpengaruh signifikan terhadap keputusan pembelian smartphone merek Samsung pada mahasiswa Universitas Alkhairaat Palu. 
Susanti, H.

\section{Pembahasan Hasil Penelitian}

Pengaruh produk, harga, tempat, dan promosi terhadap keputusan pembelian smartphone merek Samsung pada mahasiswa Universitas Alkhairaat Palu.

Hasil uji secara simultan telah terbukti bahwa variabel produk (X1), harga (X2), tempat (X3), dan promosi (X4) berpengaruh signifikan terhadap keputusan pembelian smartphone merek Samsung pada mahasiswa Universitas Alkhairaat Palu. Hal ini mengindikasikan bahwa keempat variabel tersebut dapat mendorong keputusan pembelian. Oleh karena itu, variabel bebas yaitu, variabel produk, harga, tempat dan promosi yang mempengaruhi keputusan pembelian perlu dipertahankan atau ditingkatkan.

Hasil penelitian ini sama dengan penelitian yang telah dilakukan oleh Hesti tri ayu aprilia bahwa keempat variabel bauran pemasaran yang diteliti berpengaruh terhadap keputusan pembelian smartphone android merek Samsung (studi kasus: mahasiswa Fakultas Ekonomi Universitas Muhammadiyah Jember 2011-2013).

\section{Pengaruh Produk (X1) Terhadap Keputusan Pembelian (Y) smartphone merek Samsung pada mahasiswa Universitas Alkhairaat Palu.}

Hasil uji- $\mathrm{t}$ telah terbukti bahwa produk berpengaruh signifikan terhadap keputusan pembelian smartphone merek Samsung pada mahasiswa Universitas Alkhairaat Palu. Hal ini mengindikasikan bahwa keputusan mahasiswa dalam pembelian smartphone merek Samsung ditunjang oleh produk smartphone Samsung yang memliki kualitas audio cukup jernih, menyediakan fasilitas/fitur yang lengkap, desain produk yang elegan dan menarik, merek produk yang terkenal dan mudah diingat oleh konsumen, dan variasi / tipe produk yang beraneka ragam. Hasil penelitian ini sama dengan penelitian yang dilakukan oleh Hasan et al. bahwa variabel produk mempunyai korelasi yang signifikan terhadap keputusan pembelian konsumen terhadap smartphone Blackberry.

Pengaruh Harga (X2) Terhadap Keputusan Pembelian (Y) smartphone merek Samsung pada mahasiswa Universitas Alkhairaat Palu.

Hasil uji- $\mathrm{t}$ telah terbukti bahwa harga berpengaruh signifikan terhadap keputusan pembelian smartphone merek Samsung pada mahasiswa Universitas Alkhairaat Palu. Hal ini mengindikasikan bahwa keputusan mahasiswa dalam pembelian smartphone merek Samsung didukung oleh harga yang mampu bersaing dengan smartphone merek lain, adanya diskon, harga yang bervariasi, harga yang ditawarkan sesuai dengan kualitas yang dimiliki, dan harga yang sesuai dengan manfaat yang diberikan. Hasil penelitian ini juga sama dengan penelitian yang telah dilakukan oleh Hasan et al. bahwa variabel harga mempunyai korelasi yang signifikan terhadap keputusan pembelian konsumen terhadap smartphone Blackberry.

Pengaruh Tempat (X3) Terhadap Keputusan Pembelian (Y) smartphone merek Samsung pada mahasiswa Universitas Alkhairaat Palu.

Hasil uji- $\mathrm{t}$ telah terbukti bahwa tempat berpengaruh signifikan terhadap keputusan pembelian smartphone merek Samsung pada mahasiswa Universitas Alkhairaat Palu. Sebagaimana indikator yang digunakan variabel tempat yaitu toko/counter yang mudah dijangkau, tersedianya spare part (suku cadang), ketersediaan produk, tersedianya jasa servis, dan penjualan online. Dari beberapa indikator tersebut yang memiliki pengaruh paling kuat adalah indikator ketersediaan produk. Hal ini memberi arti bahwa mahasiswa Universitas Alkhairaat Palu selalu mendapatkan produk-produk smartphone merek Samsung pada counter-counter di kota Palu

Menurut Kotler dan Amstrong (2008:63) tempat meliputi kegiatan perusahaan yang membuat produk tersedia bagi pelanggan sasaran. Maka dapat dipastikan bahwa tempat sangat berperan penting karena menjadi salah satu faktor bahan pertimbangan seorang konsumen dalam memenuhi kebutuhannya. Karena dengan adanya tempat yang strategis akan sangat memudahkan konsumen dalam menjangkaunya. 


\section{Pengaruh Promosi (X4) Terhadap Keputusan Pembelian (Y) smartphone merek Samsung pada mahasiswa Universitas Alkhairaat Palu.}

Hasil uji- $t$ telah terbukti bahwa promosi berpengaruh signifikan terhadap keputusan pembelian smartphone merek Samsung pada mahasiswa Universitas Alkhairaat Palu. Sebagaimana indikator promosi yang digunakan dalam penelitian ini yaitu iklan televisi, iklan internet, majalah, informasi dari teman, dan papan reklame. Dari beberapa indikator tersebut yang memiliki pengaruh paling kuat adalah indikator iklan televisi. Mahasiswa Universitas Alkhairaat Palu sering menemukan iklan smartphone Samsung pada media televisi sehingga mempengaruhi keputusan pembelian mereka terhadap smartphone Samsung. Namun indikator yang masih dianggap lemah adalah iklan majalah. Dikarenakan pada media cetak majalah masih kurang memuat informasi tentang smartphone merek Samsung. Mengingat majalah merupakan salah satu media yang sering digunakan oleh para mahasiswa sehingga penting bagi perusahaan smartphone merek Samsung untuk mengunakan media cetak majalah sebagai salah satu alat promosi. Hasil penelitian ini juga sama dengan penelitian yang telah dilakukan oleh Hasan et al. bahwa variabel promosi mempunyai korelasi yang signifikan terhadap keputusan pembelian konsumen terhadap smartphone Blackberry.

\section{KESIMPULAN DAN SARAN}

\section{Kesimpulan}

Berdasarkan hasil dan pembahasan yang dilakukan mengenai pengaruh bauran pemasaran terhadap keputusan pembelian smartphone merek Samsung pada mahasiswa Universitas Alkhairaat Palu, dapat ditarik kesimpulan sebagai berikut:

1. Bauran pemasaran yang terdiri dari produk, harga, tempat, dan promosi secara simultan berpengaruh signifikan terhadap keputusan pembelian smartphone merek Samsung pada mahasiswa Universitas Alkhairaat Palu.

2. Produk berpengaruh signifikan terhadap keputusan pembelian smartphone merek Samsung pada mahasiswa Universitas Alkhairaat Palu.

3. Harga berpengaruh signifikan terhadap keputusan pembelian smartphone merek Samsung pada mahasiswa Universitas Alkhairaat Palu.

4. Tempat berpengaruh signifikan terhadap keputusan pembelian smartphone merek Samsung pada mahasiswa Universitas Alkhairaat Palu.

5. Promosi berpengaruh signifikan terhadap keputusan pembelian smartphone merek Samsung pada mahasiswa Universitas Alkhairaat Palu.

\section{Saran}

Berdasarkan pada analisis dan kesimpulan yang berkaitan dengan penelitian ini, maka saran-saran yang dapat diajukan adalah sebagai berikut:

1. Dengan ditemukannya signifikansi pengaruh keempat variabel independen di atas secara simultan terhadap keputusan pembelian smartphone merek Samsung pada mahasiswa Universitas Alkhairaat Palu, diharapkan perusahaan smartphone merek Samsung untuk lebih mengembangkan stategi bauran pemasaran produknya di tengah kompetitifnya persaingan sehingga tetap mempertahankan keunggulannya sebagai penguasa pangsa pasar smartphone dunia.

2. Kepada perusahaan smartphone merek Samsung diharapkan dapat memberikan manfaat yang lebih baik agar sesuai dengan harga yang harus dibayarkan oleh konsumen.

3. Kepada perusahaan smartphone merek Samsung diharapkan dapat mendistribusikan spare part smartphone Samsung kepada seluruh counter-counter yang ada di kota Palu. 
Susanti, H.

4. Kepada perusahaan smartphone merek Samsung diharapkan lebih inovatif dalam memodifikasi dan mendesain produknya sehingga konsumen dapat lebih tertarik untuk menggunakan smartphone merek Samsung.

5. Kepada perusahaan smartphone merek Samsung diharapkan dapat memperluas media untuk mempromosikan produknya agar mampu mencapai semua kalangan terutama mahasiswa.

\section{REFERENSI}

Apriliana, Hesti Tri Ayu \& Seno Sumowo (2015). Analisis Variabel-Variabel Yang Mempengaruhi Keputusan Pembelian Smartphone Android Merek Samsung (Studi Kasus: Mahasiswa Fakultas Ekonomi Manajemen Universitas Muhammadiyah Jember 2011 - 2013). Jurnal Manajemen dan Bisnis Indonesia, Vol 1, No 1, Halaman 31 - 45

Assauri, 2009. Manajemen Pemsaran (Dasar, Konsep Dan Strategi). Edisi Ke-1, Penerbit PT. Rajagrafindo Persada, Jakarta

Boyd, Harprer W., Orville C. Walker, Jean-Claude Larrece (2000). Manajemen Pemasaran. Erlangga. Jakarta

Firdaus, Muhammad, (2004). Ekonometrika Suatu Pendekatan Aplikasi. Cetakan Pertama. PT.Bumi Aksara, Jakarta

Hasan, Alizar., Yumi Meuthia., Berry Yuliandra., \& Indah Desfita (2014). Analisis Bauran Pemasaran Terhadap Keputusan Pembelian Smartphone Blackberry Dan Samsung Android. Jurnal Optimasi System Industri, Vol 13, No 2, Halaman 687 - 706

Husin, Nurmubin, (2014). Pengaruh Bauran Pemasaran Jasa Terhadap Keputusan Nasabah dalam Pembelian Produk Mulia (Emas) pada PT. Pegadaian (Persero) cabang Syariah di Kota Palu. Skripsi. Fak. Ekonomi Untad.

Kotler, Philip \& Gerry Armstrong, (2008). Prinsip-prinsip pemasaran. (Edisi 12, jilid 1). Erlangga. Jakarta.

Kotler, Philip \& Kevin Lane Keller, (2009). Manajemen pemasaran. (Edisi 13, jilid 1). Erlangga. Jakarta.

Mowen C, John., \& Michael Minor, (2002). Perilaku Konsumen. (Edisi 5, Jilid 1). Erlangga. Jakarta. Setiadi J, Nugroho., (2013). Perilaku Konsumen. Prenada Media. Jakarta. Sugiyono.

(2014). Metode Penelitian Bisnis . Alfabeta. Bandung.

\section{Sumber Lain}

https://gadgetren.com/2016/11/01/samsung-masih-raja-smartphone-dunia-di-q3-tahun-2016oppodan-huawei-peringkat-berapal 